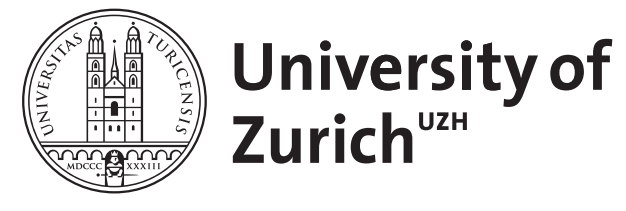

Zurich Open Repository and Archive

University of Zurich

University Library

Strickhofstrasse 39

CH-8057 Zurich

www.zora.uzh.ch

Year: 2011

\title{
Just a supraventricular tachycardia
}

Balmer, C ; Gass, M

Posted at the Zurich Open Repository and Archive, University of Zurich

ZORA URL: https://doi.org/10.5167/uzh-53090

Journal Article

Published Version

Originally published at:

Balmer, C; Gass, M (2011). Just a supraventricular tachycardia. Cardiovascular Medicine, 14(10):294296. 


\section{Just a supraventricular tachycardia}

Christian Balmer, Matthias Gass

Universitätskinderspital, Zürich, Switzerland

\section{Case report}

A 16-year-old female was seen for recurrent episodes of supraventricular tachycardia. She experienced episodes of palpitation once or twice a week, mostly triggered by physical activity. During these episodes, the patient felt dizzy and also noted fast pulsations in the neck region. The tachycardia episodes stopped after 10 to 15 minutes either spontaneously or with a Valsalva manoeuvre.

In this patient, recurrent tachycardia occured since infancy and she had to undergo medical conversion with adenosine at the age of 6 weeks and 2 years, respectively. Prophylactic antiarrhythmic therapy with propranolol was given for one year. The patient remained asymptomatic until the age of 13 years. The tachycardia occurred again with increasing frequency and intensity thereafter. The ECG of a recent episode showed a narrow complex tachycardia at a rate of 150 beats per minute. Our differential diagnosis was AV nodal reentrant tachycardia and AV reentrant tachycardia. The age and gender of the patient as well as the symptoms with "pulsations at the neck" suggests an AV nodal reentrant tachycardia while the early onset of the tachycardia in infancy is more typical for an AV re-entrant tachycardia. The patient was brought forward for an electrophysiology study with the aim to either modulate the slow pathway of the AV node or to ablate the accessory pathway. With programmed atrial stimulation, with a singular extrastimulus (S1S1 $500 \mathrm{~ms}$, S1S2 $340 \mathrm{~ms}$ ), the tachycardia could be induced; the surface ECG is shown in figure 1.

\section{Questions}

Can you identify the $\mathrm{P}$ waves? What would you conclude from the relation of the $\mathrm{P}$ waves to the QRS complexes? What is your diagnosis? 
Figure 1

12 lead surface ECG during electrophysiological study with induction of the tachycardia, see text (speed $50 \mathrm{~mm} / \mathrm{s}$ ).

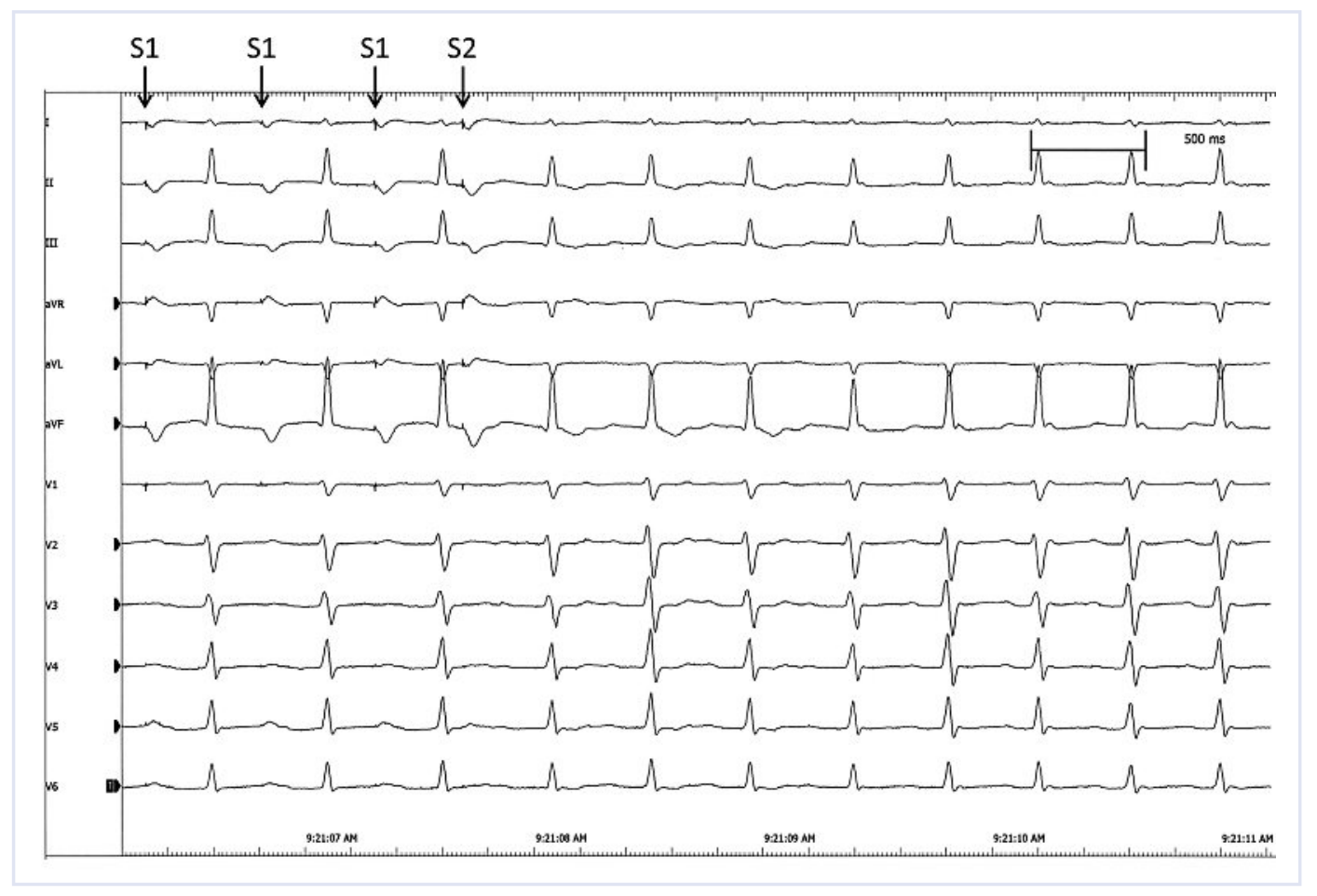

\section{Answers}

The surface ECG in figure 1 shows a regular tachycardia with narrow QRS complexes at a rate of $152 \mathrm{bpm}$. The tachycardia starts after programmed stimulation in the right atrium. Stimulation traces in the atrial drive train (S1) can be identified, preceeding each $\mathrm{P}$ wave, in the first 3 beats. Then, after the atrial extrastimulus (S2), the tachycardia is induced. The first 3 beats of the tachycardia (QRS complexes $\mathrm{N}^{\circ} 4$ to 6 ) are followed by a small biphasic $\mathrm{P}$ wave with a long R-P interval of $154 \mathrm{~ms}$, best seen within the ST segment in II and aVF $\left(^{*}\right)$. Later (from QRS complex $\mathrm{N}^{\circ} 6$ onwards), the $\mathrm{P}$ wave is just behind the QRS complex with a short R-P interval of $52 \mathrm{~ms}$, suggesting a short retrograde activation (**). The explanation for this phenomenon can be seen in the intracardiac leads (fig. 3): The induced tachycardia is an orthodromic AV re-entrant tachycardia with antegrade conduction over the AV node and retrograde conduction over a left lateral accessory pathway (concealed Wolff Parkinson White Syndrome). The earliest retrograde activation of the atrium is seen in the distal coronary sinus (CS 1, 2 and CS 3,4). The activation then spreads over the atria and reaches the high right atrium relatively late (solid line). After 3 beats of tachycardia, there is a complete change in the activation pattern and a typical (slow-fast) AV nodal reentrant tachycardia is induced. The earliest atrial activation occurs at the coronary sinus ostium (CS 7, 8 and $\operatorname{CS~9,10)~and~retrograde~}$ atrial activation occurs almost simultaneously with the antegrade ventricular activation (dotted line).

After having identified the mechanism of the tachycardia, the slow pathway was successfully modulated with 3 applications of radiofrequency energy. Later a transseptal puncture was performed and the mapping of the mitral valve anulus showed the earliest atrial activation (and also fusion of the ventricular and atrial signal) in an inferior-posterior position. Radiofrequency ablation in this position induced a permanent block in the accessory pathway. The postinterventional course was uneventful and the patient remained asymptomatic thereafter.

\section{Comments}

Invasive electrophysiology studies and radiofrequency ablations have become standard procedures in the treatment of supraventricular tachycardia in adults and also in children with a high efficacy and a low rate of complication $[1,2]$. The knowledge about the genesis and mechanisms of supraventricular tachycardia is steadily growing through the analysis of intracardiac ECGs and thus allows a deeper understanding of the changes in the surface ECG, seen during tachycardia. The presence of a dual AV node physiology with inducible AV nodal reentrant tachycardia has been seen in 1 to $8 \%$ of patients with Wolff Parkinson White Syn- 
Figure 2

12 lead surface ECG during electrophysiological study with induction of the tachycardia, see text (speed $50 \mathrm{~mm} / \mathrm{s}$ ).

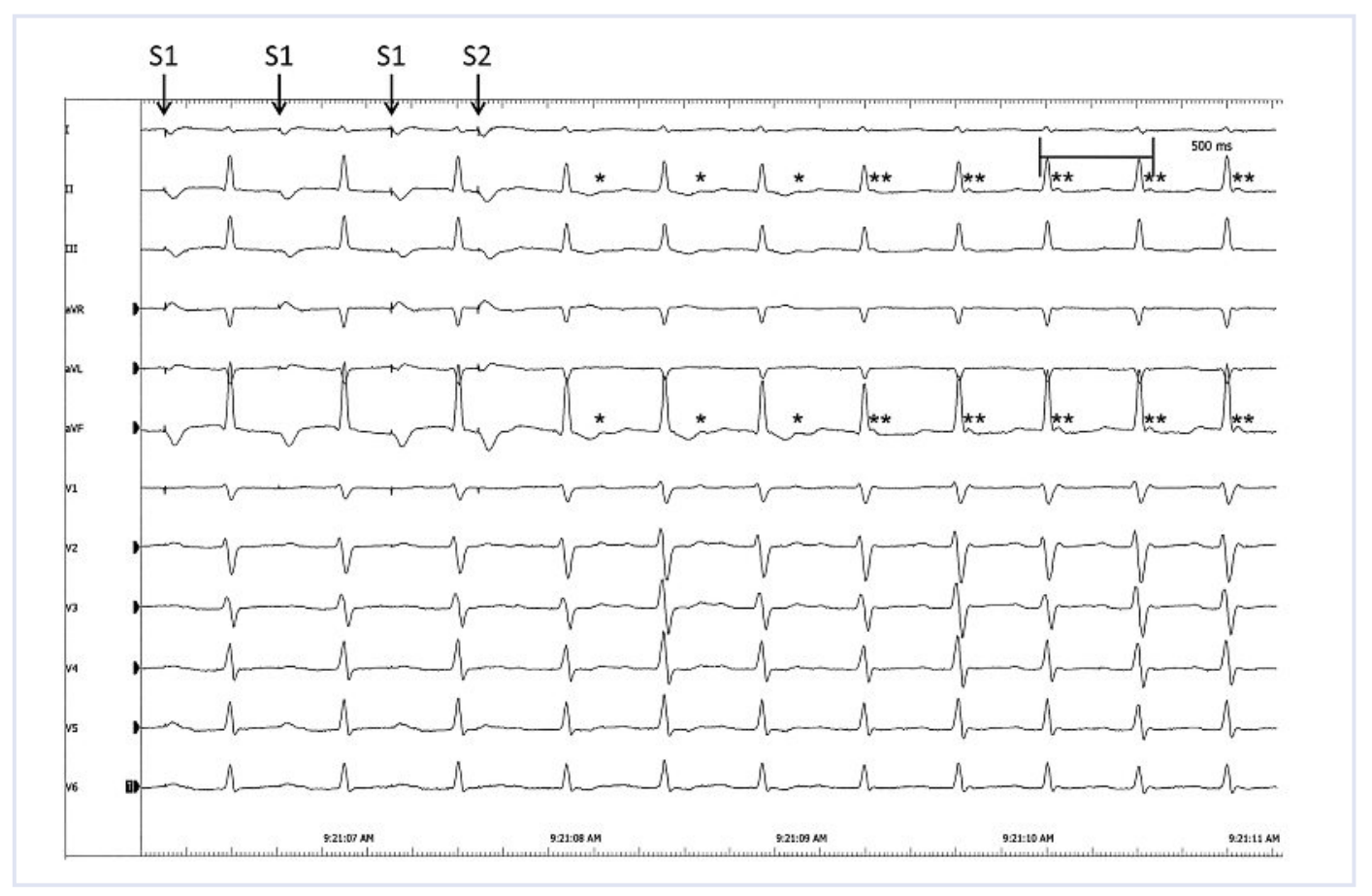

Figure 3

Simultaneous intracardiac leads corresponding to figure 2 with catheters positioned in the right atrium (HRA), the coronary sinus (CS 1,2 = proximal, CS 9,10 = distal) and the right ventricle (RVA) $($ speed $100 \mathrm{~mm} / \mathrm{s})$.

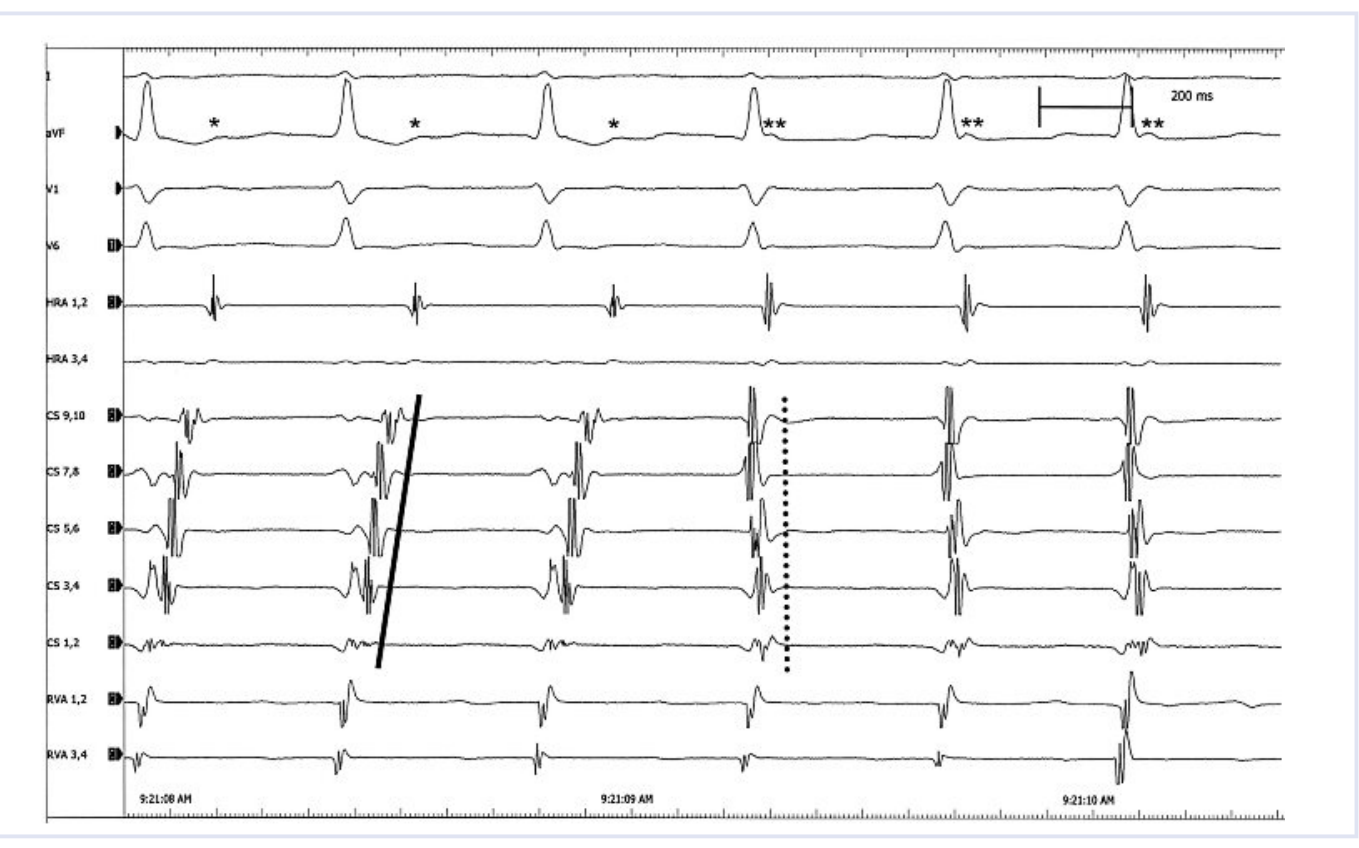

drome $[3,4]$. In our patient, the accessory pathway was a part of the tachycardia reentry mechanism and not only a bystander.

\section{References}

1 Spector P, Reynolds MR, Calkins HR, Sondhi M, Xu Y, Martin A, et al. Meta-analysis of atrial flutter and supraventricular tachycardia. Am J Cardiol. 2009;104:671-7.
2 Samii SM, Cohen MH. Abation of tachyarrhythmias in pediatric patients. Curr opin Cardiol. 2004;19:64-7.

3 Wenig KP, Wolff GS, Young ML. Multiple acessory pathways in pediatric patients with wolff parkinson white syndrome. Am J Cardiol. 2003;91:1178-83.

4 Lee PC, Hwang B, Chen YJ, Tai CT, Chen SA, Chiang CE. Electrophysiologic characteristics and radiofrequency catheter ablation in children with Wolff Parkinson White Syndrome. PACE. 2006;29:490-5. 